\title{
Anterior communicating artery complex aneurysms: anatomic characteristics as predictors of surgical outcome in 300 cases
}

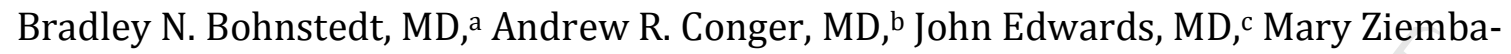

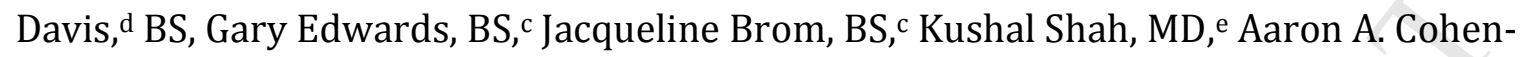
Gadol, MD, MSc, MBA,

aOklahoma University Health Sciences Center, Oklahoma City, Oklahoma

bDepartment of Neurosurgery, Geisinger Medical Center, Danville, Pennsylvania

${ }^{\mathrm{c} G o o d m a n}$ Campbell Brain and Spine, Department of Neurological Surgery, Indiana

University School of Medicine, Indianapolis, Indiana

dIndiana University Health, Indianapolis, Indiana

eUniversity of Kansas Medical Center, Kansas City, Kansas

fIndiana University Simon Cancer Center, Indianapolis, Indiana

\section{Correspondence:}

Aaron A. Cohen-Gadol, MD, MSc, MBA

Goodman Campbell Brain and Spine

Department of Neurological Surgery

Indiana University School of Medicine

355 W. 16th St, Suite 5100

Indianapolis, IN 46202

E-mail: acohenmd@gmail.com

\section{E-mail addresses:}

Bradley N. Bohnstedt: Bradley-Bohnstedt@ouhsc.edu

Andrew R. Conger: Aconge@lsuhsc.edu

Mary Ziemba-Davis: mxziemba@stvincent.org

Gary Edwards: garyrobertedwards@gmail.com

Kushal Shah: kjs5wf@mail.umkc.edu

Jacqueline Brom: brom2@uic.edu

Aaron A. Cohen-Gadol: acohenmd@gmail.com

Running Title: Microsurgery of ACoA Aneurysms

Financial Support: This research did not receive any specific grant from funding agencies in the public, commercial, or not-for-profit sectors.

Key Words: anterior communicating artery, intracranial aneurysm; clip ligation, microsurgery; treatment outcome; anatomy

This is the author's manuscript of the article published in final edited form as:

Bohnstedt, B. N., Conger, A. R., Edwards, J., Ziemba-Davis, M., Edwards, G., Brom, J., ... Cohen-Gadol, A. A. (2018). Anterior communicating artery complex aneurysms: anatomic characteristics as predictors of surgical outcome in 300 cases. World Neurosurgery. https://doi.org/10.1016/j.wneu.2018.10.172 


\section{ABSTRACT}

OBJECTIVE: Anterior communicating artery ( $\mathrm{ACoA})$ complex aneurysms are challenging to treat microsurgically. The authors report their experience with microsurgical treatment of $\mathrm{ACoA}$ aneurysms and examine the anatomic characteristics of these aneurysms as predictors of outcome.

METHODS: The authors queried their institution's aneurysm database for records of consecutive patients treated for ACoA aneurysms via microsurgical clip ligation. Data included patient demographics and clinical/radiographic presentation characteristics as well as operative techniques. Glasgow outcome scores (GOS) at hospital discharge and 6month as well as 1-year follow-up were analyzed.

RESULTS: Of 319 ACoA aneurysms that underwent treatment, 259 were ruptured and 60 were unruptured. Average GOS at 1-year follow-up for all patients was 4.6. Average GOS for patients with ruptured aneurysms correlated with Hunt and Hess grade at presentation, presence of frontal hemorrhages, and need for multiple clips during surgery. Notably, 142 (44.5\%) of aneurysms originated mainly from the ACoA artery; 12 (3.8\%) primarily from the A1 branch; 3 (0.9\%) from the A2 branch; and 162 (50.8\%) from the A1/A2 junction. Aneurysm projection was superior in 118 (37\%), inferior in 106 (33.2\%), anterior in $88(27.6 \%)$, and posterior in $7(2.2 \%)$. Patients with aneurysms originating from the A1 segment had worse outcomes. Posteriorly-projecting aneurysms were more likely to be unruptured and larger than other aneurysm configurations. CONCLUSIONS: The aneurysm's exact location in relation to the adjacent neurovascular structures is potentially predictive of outcomes in the microsurgical treatment of ACoA aneurysms. 


\section{INTRODUCTION}

Aneurysms in the anterior communicating artery (ACoA) complex present special challenges during both microsurgical and endovascular treatment. The anatomy of the anterior cerebral arteries and the recurrent artery of Huebner, the ACoA itself, and their associated perforators is highly variable. ${ }^{1}$ As a result, there are numerous possible configurations and emergence sites for aneurysms involving this complex. ${ }^{2}$ This variability results in higher rates of complications and vascular stenosis/occlusion during microsurgery compared with aneurysms in other locations. ${ }^{3}$ In addition, surgical risk is higher for patients with these aneurysms because of the need for brain retraction, gyrus rectus resection and manipulation of the arteries of the ACoA complex that perfuse the deep structures including the hypothalamus, septal region and optic apparatus. ${ }^{4,5}$ ACoA aneurysms have also been shown to have higher risk of intraoperative rupture compared to those in other locations, ${ }^{6,7}$ adding to their surgical complexity.

Despite the elevated risk of surgical morbidity, microsurgical clipping is an important treatment modality in select aneurysms because other management options also present unique challenges. The ACoA aneurysms may have an increased propensity to hemorrhage at or below sizes that are considered safe for conservative management of aneurysms in other locations, ${ }^{4,8-12}$ and hemorrhages can occur more often in younger patients who have fewer risk factors for rupture.9,11 The increased likelihood of hemorrhage decreases the threshold of conservative management.

Furthermore, some ACoA aneurysms carry a wide neck-to-dome ratio, necessitating stent placement for endovascular coiling. This need increases catheter time and risk of periprocedural morbidity, ${ }^{13}$ while potentially exposing the patient to higher risks of recurrence, hemorrhage and retreatment. ${ }^{14,15}$ Additionally, stent placement in the setting of SAH requires dual antiplatelet agents, also increasing the risks.

In this article, we present our management strategies and outcomes for patients with microsurgically treated ACoA aneurysms. Data are analyzed first by vessel of origin, then by the direction of aneurysm projection, followed by surgical side of approach in correlation with the side of aneurysm origin, and finally by clinical indicators to help predict outcome following microsurgical treatment. The intent of this analysis is to identify 
factors that may help predict outcome and thereby are likely to guide and improve future treatment of these aneurysms.

\section{METHODS}

Following Indiana University Institutional Review Board approval, we performed a retrospective review of the records of patients who have been prospectively enrolled in our database. Our database search revealed records of 2,152 patients who presented with intracranial aneurysm(s) from January 2000 through December 2010.

Twenty percent $(438$ of 2,152) of the patients whose records were included in the database harbored aneurysms located near the ACoA complex. Of these 438 patients, 319 were treated with microsurgical clip ligation and they constitute our study population (the rest were managed via endovascular techniques). Assessment of aneurysms was performed using computed tomography angiography (CTA), catheter-based cerebral angiogram, or magnetic resonance angiography (MRA). If multiple aneurysms were found in a patient with subarachnoid hemorrhage, determination of the ruptured aneurysm was made by the attending neurosurgeon in consultation with an interventional neuroradiologist and based on imaging and/or intraoperative findings.

Patients suffering from ruptured aneurysms were discussed between at least one microsurgeon and interventionalist before treatment was rendered. Younger patients and those with aneurysms that were not easily amendable to endovascular treatment underwent clip ligation. Of the 319 aneurysms microsurgically treated, 60 were unruptured and 259 were ruptured. Women represented 60.5\% (193) and men comprised $39.5 \%$ (126) of our study population.

Data was recorded from the time of admission until hospital discharge, death, or loss to follow-up. Patient characteristics included age, race, sex, and medical history. Presentation characteristics included presence of subarachnoid hemorrhage, intracranial hemorrhage (ICH), Hunt and Hess grade $(\mathrm{HH})^{16}$, and Fisher grade. ${ }^{17}$ Aneurysm characteristics included side of origin (right or left), size in millimeters (mm), multilobed morphology, presence of calcification on imaging, previous treatment(s) rendered, and whether there was a remnant on posteoprative imaging. Operative data included surgical approach (ipsilateral or contralateral), frontal lobe ICH evacuation, intraoperative rupture, 
number and type of aneurysm clips used, intraoperative imaging, and the need for clip adjustment following intraoperative imaging. Postoperative complications recorded included hydrocephalus, vasospasm, and ischemia. Clinical outcomes were assessed via the Glasgow outcome scale (GOS) ${ }^{18}$ at discharge, 6-month, 1-year, and final follow-up examinations. Acceptable GOS outcomes were defined as GOS scores of 4 or 5.

These variables were examined in relation to the artery of origin $\mathrm{ACoA}, \mathrm{A} 1, \mathrm{~A} 2$, or the A1/A2 junction), direction of aneurysm projection (superior, inferior, anterior, posterior), and ipsilateral versus contralateral surgical approach relative to the dominant A1 branch. A research nurse recorded all the outcome data independent of the surgeon's judgment. Acceptable outcomes were defined as GOS scores of 4 or 5 at discharge following microsurgical clip ligation.

\section{Statistical Analysis}

Minitab 16 (State College, PA) was used for statistical analyses. Pearson's chisquare $\left(\mathrm{X}^{2}\right)$ and analysis of variance (ANOVA) were used to examine the relationship between univariate variables and the (a) artery of origin and (b) direction of aneurysm projection. $\mathrm{X}^{2}$ was used to analyze the proportion of patients with acceptable GOS outcomes based on the direction of aneurysm projection and side of surgical approach. Variations in discharge and final GOS scores based on the complexity of ruptured aneurysms were assessed by means of the Student's $t$-test and ANOVA. Probability $(p)$ values associated with Fishers exact test were reported for $2 \times 2 \mathrm{X}^{2}$ tables. Yates correction for continuity was used if expected frequencies were less than 5 in $2 \times 2 \mathrm{X}^{2}$ tables.

\section{RESULTS}

Patients, presentation, aneurysm characteristics, operative events, postoperative complications, and clinical outcomes are presented by (a) artery of origin (Table 1) and (b) the direction of aneurysm projection (Table 2). These results are followed by an analysis of discharge outcomes based on the direction of aneurysm projection and contralateral versus ipsilateral surgical approach (Table 3). Concluding analyses focusing only on ruptured ACoA aneurysms demonstrate clinical outcomes based on case complexity (Table 4), and the relationship between Hunt and Hess grade at admission and acceptable GOS 
outcomes (Table 5). All patients underwent postoperative angiography. Small aneurysm remnants underwent follow up imaging. Standard follow-up imaging included CTA at 1, 5 and 10 years postoperatively.

\section{Analysis by Artery of Origin}

Analysis of the aneurysms based on their artery of origin revealed 142 (44.5\%) aneurysms originating primarily from the ACoA artery, 12 (3.8\%) from the A1, $3(0.9 \%)$ from the $\mathrm{A} 2$, and 162 (50.8\%) from the A1/A2 junction (Table 1). The average age of patients was 50.4 years with patients suffering from hypertension (43.7\%), family history of subarachnoid hemorrhage (11.3\%), diabetes (4.4\%), hyperlipidemia (9.4\%), and history of smoking (63.8\%). Ruptured aneurysms comprised $81.2 \%$ of patients, and $17 \%$ presented with frontal lobe ICH. The average Hunt-Hess grade at presentation was 2.1 and the average Fisher grade was 3.0. The average aneurysm size was $6.8 \mathrm{~mm}$. Among all lesions, $27.3 \%$ of aneurysms were multi-lobed, $4.4 \%$ were calcified, and $1 \%$ had been previously coiled.

Craniotomy was performed on the side ipsilateral to the dominant A1 artery 91.4\% of the time. A contralateral ICH guided the side of approach. An intraparenchymal clot was evacuated in $43.2 \%$ of the patients presenting with ICH. The aneurysm ruptured intraoperatively in $3.2 \%$ of patients. A temporary clip was used in $85 \%$ of patients. Clip configurations used were single curved/angled in $24.5 \%$, single straight in $20 \%$, single fenestrated in $35.8 \%$, and multiple clips in $16.1 \%$. Intraoperative angiogram was used in $44.6 \%$ of the patients, Indocyanine green fluorescence imaging was used in $4.5 \%$, and both types of imaging were used in $4.1 \%$. Intraoperative imaging resulted in adjustment of the clip in $25.8 \%$ of the time.

Postoperatively, 28.2\% of patients developed hydrocephalus (most common in the aneurysms originating from the A1 segment), 20.3\% of patients suffered from a radiographic infarction (including any asymptomatic hypodensity that could be retractionrelated)(least common in those with aneurysms originating from the A1), 26.3\% suffered from a new postoperative deficit (including any minor temporary deficits), and 18.5\% were treated for vasospasm. Aneurysm remnants were found in $6.6 \%$ of patients on 
postoperative imaging. There were no statistical differences between arteries of origin and the previously mentioned characteristics.

Patients with aneurysms originating from the ACoA and the A1/2 junction showed a trend toward being present in patients with younger age (average of 49.6 and 50.5 years, respectively) in comparison with those whose aneurysms that were based on the A1 or A2 alone (57.3 and 58.0 years, respectively, $\mathrm{p}=0.092$ ). Aneurysms originating mainly from the A2 alone tended to be larger (average of 10.0 vs. $6.8 \mathrm{~mm}, \mathrm{p}=0.087$ ). GOS scores were worst for patients whose aneurysms originated mainly from the A1 segment alone $(p=.028)$ (Table 1).

Patients with A1 aneurysms experienced notably higher vasospasm rates compared with the total study population ( $41.7 \%$ vs $18.5 \%$ ); however, this did not reach statistical significance. In this series, A2 aneurysms more frequently required intraoperative angiography and clip adjustment (66.7\% of the time) and were more likely to have a remnant that showed on postoperative angiography (33\% of the time), but each of these characteristics failed to reach statistical significance.

\section{Analysis by Aneurysm Projection}

Aneurysms projected superiorly in 118 patients (37.0\%), inferiorly in 106 (33.2\%), anteriorly in 88 (27.6\%), and posteriorly in 7 (2.2\%) (Table 2). Patients with inferiorlyprojecting aneurysms had a small but statistically significant age difference in comparison with the entire group ( 47.2 vs. 50.4 years, $\mathrm{p}=0.006$ ). This subset of aneurysms was also more likely to present with rupture than the group as a whole (85.9 vs. 81.2\%, p=.034) and less likely than the overall group to require an intraoperative angiogram (26.9 vs. $44.6 \%$, $\mathrm{p}=0.0001$ ). Posteriorly-projecting ACoA aneurysms were likely to be larger than the average (11.8 vs $6.8 \mathrm{~mm}, \mathrm{p}=0.0001$ ), less likely to present with rupture ( $42.9 \mathrm{vs.} 81.2 \%$, $\mathrm{p}=0.034$ ), and the most likely to require intraoperative angiography (71.4 vs. $44.6 \%$, $\mathrm{p}=0.0001$ ). Anteriorly-projecting aneurysms were more likely to present with higher Fisher grades than superiorly- or inferiorly-projecting aneurysms $(p=0.049)$. The postoperative comparative rates of radiographic infarct, neurological deficit, aneurysmal remnant, and vasospasm failed to reach statistical significance. 


\section{Discharge Outcomes, ACoA Aneurysm Projection, and Surgical Approach}

The best outcomes (all patients resulted in GOS scores of 4 or 5 ) were seen in posteriorly projecting aneurysms via an ipsilateral approach and superiorly projecting aneurysms via a contralateral approach to the dominant A1 arteries (Table 3). The poorest outcomes were seen with inferior projecting aneurysms approached from the contralateral side. Overall acceptable outcome was found in $67.5 \%$ of all microsurgically managed ruptured ACoA aneurysms.

\section{Ruptured ACoA Aneurysms: Clinical Outcomes by Indicators of Aneurysm Complexity}

Table 4 correlates indicators of aneurysm complexity with GOS. Of note, patients with a frontal lobe intraparenchymal hemorrhage had a statistically worse GOS at discharge (3.3 vs. 3.9, p=.008) and a trend toward worse GOS at follow-up (3.7 vs 4.2, $\mathrm{p}=.085$ ) compared to those without a frontal lobe hemorrhage. This difference persisted regardless of whether the hematoma was evacuated or not. Evacuation of associated intraparenchymal hemorrhages did not appear to significantly improve outcomes at discharge or follow-up ( $\mathrm{p}=0.736$ and 0.798$)$. Aneurysms requiring more than one clip and aneurysms requiring the use of a fenestrated clip had statistically significant worse GOS at discharge (3.3 vs 4.1 and 3.6 vs 4.1, respectively, $\mathrm{p}=.009$ ) and a trend toward worse outcomes at follow-up (4.2 vs 3.6 and 4.2 vs 3.9 respectively, $p=.069$ ) than those requiring only one nonfenestrated clip.

\section{Ruptured ACoA Aneurysms: Glasgow Outcome Score Based on Presenting Hunt and Hess} Score

Table 5 correlates the Hunt \& Hess scores from ruptured ACoA aneurysms with the GOS. A GOS of 4 and 5 were considered acceptable. As expected, a poor HH grade at presentation correlated to a worse GOS at both discharge and latest follow-up. The majority of the patients in the study population presented with a HH grade of 1.

\section{DISCUSSION}

In our study, for patients with unruptured aneurysms, the average GOS was 4.6 at discharge and 4.8 at 6 and 12 months, respectively. The percentage of patients with an 
acceptable outcome (GOS of 4 or 5 ) was $92 \%$, whereas $8 \%$ had a GOS of 3 . There was no mortality in this group. These results are consistent with other series of unruptured ACoA aneurysms. ${ }^{19,20}$

For patients with ruptured aneurysms, the average GOS score was 3.8 at discharge and at 6 months, and 4.0 at 12 months. The percentage of patients with an acceptable outcome (GOS of 4 or 5) after suffering a subarachnoid hemorrhage from an ACoA aneurysm who underwent microsurgical clip ligation in our series was $67.5 \%$ at last follow-up. This is consistent with the ISAT data: 1 year after treatment, $69.4 \%$ of all patients with subarachnoid hemorrhage who had undergone microsurgical clipping demonstrated a favorable outcome. ${ }^{21}$ The average size of ruptured ACoA aneurysms in our series was $6.65 \mathrm{~mm}$. This is consistent with other reports of ACoA aneurysms rupturing at a size smaller than $7 \mathrm{~mm}$, which is commonly thought to be a size safely observed.4, 8-12

\section{Analysis by Artery of Origin}

Aneurysms of the proximal ACA territory are rarely based at one artery, they are typically based at the branching points of the ACoA and the A1/A2 junction. In our series, $50 \%$ of the ACoA complex aneurysms originated primarily from the A1/A2 junction and $44.5 \%$ arose mainly from the ACoA itself. Patients with aneurysms originating mainly from the ACoA and the A1/A2 junction were younger (average of 49.6 and 50.5 years, respectively) than those whose aneurysms originated primarily from the A1 or A2 alone (57.3 and 58.0 years, respectively). There are few studies of ACoA aneurysms originating from A1 or A2 alone as these lesions are rare, comprising $<1 \%$ of all aneurysms, ${ }^{10,21}$ and these studies did not address age differences.

One explanation for the difference in ages suggests that a slower rate of aneurysm formation in A1 and A2 segment aneurysms may result from a less forceful vector on the vessel walls due to the smaller volume of blood traversing the perforating vessels that usually give rise to A1 and A2 segment aneurysms. The few published studies found that aneurysms of the A1 or A2 segments often occur at the origin of perforators, have thin walls, and rupture at smaller sizes than aneurysms at other locations. ${ }^{10,22}$ In our population, we found the opposite to be true, with average presenting sizes being $8.8 \mathrm{~mm}$ for A1 aneurysms and $10.0 \mathrm{~mm}$ for A2 aneurysms; however, due to the small sample size, 
these sizes were not statistically different from the $6.8 \mathrm{~mm}$ average size for all ACoA complex aneurysms.

In our series, patients with A1 aneurysms were found to have higher average rates of symptomatic vasospasm in comparison with the entire group (41.7 vs $18.5 \%$, respectively). This may explain why the GOS scores for patients with A1 aneurysms were worse at all time points (3.0, 3.4, and 3.0, at discharge, 6 months, and 12 months after treatment, respectively) when compared with the overall averages of aneurysms at other locations at those same time points $(4.0,4.5$, and 4.6 , respectively).

Abla et al. ${ }^{23}$ found that patients with pericallosal aneurysms had a higher rate of symptomatic vasospasm than those with aneurysms in other locations, despite a smaller clot burden on imaging. The small caliber of the pericallosal vessels and the extent of collateral supply may be responsible for this finding. Perhaps vasospasms of the perforating vessels associated with the A1 segment are more likely the cause of this ironic finding.

Aneurysms originating from the A2 segment in our series were more likely to require intraoperative digital subtraction angiography (DSA), clip adjustment and carry a remnant on follow-up angiography, in comparison with aneurysms from other sites of origin. Although this finding did not reach statistical significance, the hidden location of the neck within the interhemispheric fissure and medial to the A2 segment compromises the direct visualization of the A2 segment and its branches/perforators.

\section{Analysis by Aneurysm Projection}

Understanding the orientation or projection of the dome of the ACoA aneurysm may direct the surgeon to avoid injury to critical structures and minimize the risk of intraoperative hemorrhage. The direction of projection of the ACoA aneurysm is based on the plane of the A2 vessels. Microsurgical clipping strategies have been described based on this classification. ${ }^{24}$ With a posteriorly-projecting dome, the recurrent artery of Heubner and the contralateral A1 may be at increased risk. Inferiorly-projecting aneurysms can be adherent to the optic apparatus, interfering with proximal control on the contralateral A1. With superiorly-projecting aneurysms, the contralateral A2 may be difficult to visualize. The gyrus rectus is often resected for superiorly- and posteriorly-projecting 
aneurysms. Proust et al. ${ }^{3}$ reported using the direction of dome projection as a criterion for deciding which ACoA aneurysm to clip and which to coil. Patients with aneurysms that were directed posterior to the plane of the A2 vessels were noted to have worse outcomes with clip ligation. There is a higher risk of ACoA perforator injury if the aneurysm is projecting superiorly and posteriorly. In addition, more extensive gyrus rectus resection is necessary in these cases. However, in our cohort, patients with posterior projecting aneurysm did not suffer from worse outcomes. This finding is most likely related to the small sample size or the fact that 4 of 7 of these aneurysms were unruptured at the time of their microsurgical clipping.

Furthermore, DeBono et. al. ${ }^{25}$ found better GOS scores among patients with anteriorly-projecting ACoA aneurysms. In our series, there were no statistical differences in outcomes or complications based on the direction of ACoA dome projections. However, there was an increase in the rates of postoperative deficits and clinical vasospasms in patients with posteriorly-projecting aneurysms. In contrast with our expectation, there were actually fewer radiographic infarctions in these patients compared with those who harbored anteriorly-projecting aneurysms. Nonetheless, in our practice, we have been more likely to treat our patients with posterior projecting aneurysms via endovascular options since the risk of neuropsychological deficits (not studied here) is more likely.

In our series, inferiorly-projecting aneurysms were associated with younger patient age, more likely to present with rupture, and less likely to require intraoperative DSA, all of which were statistically significant. The reason for the differences in patient age and rupture risk are not clear, but may be related. Given the general anterocranial orientation of these vessels, it may be that an inferiorly-directed vector of flow into the sac may have a more significant hemodynamic effect on the vessel wall, causing aneurysms to develop more rapidly and rupture earlier.

Posteriorly-directed aneurysms tended to be larger and less likely to present with rupture. This is consistent with a vessel wall subjected to a smaller magnitude of flow vector. Additionally, the requirement for intraoperative DSA is likely due to anatomy. Inferiorly-projecting aneurysms are easier to investigate under direct microscopic visualization, whereas posteriorly-projecting aneurysms present more of a challenge, increasing the likelihood that intraoperative DSA will be necessary. 
In our series, patients with anteriorly-projecting aneurysms were more likely to present with a worse Fisher grade. This is likely due to the anatomic characteristics of the region, and the likelihood of an anteriorly-directed aneurysm to fill the basal cisterns with blood. Although differences in the projection of ACoA aneurysms have been well documented with respect to treatment, there is little data regarding the specific characteristics discussed here.

\section{Discharge Outcomes by Aneurysm Projection and Surgical Approach}

ACoA aneurysms are usually approached surgically via the side ipsilateral to the dominant A1. This approach permits early dissection of the dominant blood supply and aneurysm neck while avoiding the dome. Other considerations that may influence the side of operative approach include hemispheric dominance and the presence of an intracerebral hematoma and/or the presence of multiple aneurysms. In our series, craniotomy was performed ipsilateral to the dominant A1 segment $91.4 \%$ of the time.

An important subset in our series was patients with superiorly-projecting aneurysms that were approached ipsilateral to the dominant A1. There were 99 patients in this group, and $58.6 \%$ of them had acceptable outcomes. Aneurysms with this orientation were approached contralateral to the dominant A1 in 10 patients with $100 \%$ acceptable outcome. One reason for this discrepancy in outcomes may be the relative position of the A2 branches in relationship to a superiorly-projecting aneurysm. Hyun et al. ${ }^{26}$ suggested approaching superiorly-projecting aneurysms from the side of the most posteriorlypositioned A2 branch. This provides a better view of both A2 branches and the superiorlyprojecting aneurysm in between the branches. ${ }^{26}$ Suzuki et al. ${ }^{27}$ approached superiorlyprojecting aneurysms from the side of the fundus projection. These authors identified a distinct group of patients with superiorly-projecting aneurysms characterized by a closed A2 plane who suffered from a higher rate of surgical complications such as vascular injury and cerebral contusion. As a result, superiorly-projecting ACoA aneurysms should be carefully evaluated with respect to the laterality of surgical approach.

\section{Ruptured ACoA Aneurysms: Clinical Outcomes by Indicators of Aneurysm Complexity}


As mentioned in our previous analysis, outcomes for A1 aneurysms was worse compared with aneurysms from other vessels of origin. However, during this subset of analysis, we found a statistically significant difference in outcome only at final follow-up. In addition, patients presenting with frontal lobe hemorrhages had worse outcomes both at discharge and final follow-up; interestingly, their outcomes were not improved by clot evacuation. It is quite possible that the patients who required clot evacuation were predisposed to a worse outcome.

We often used fenestrated clips in our series. Superiorly- and posteriorly-projecting aneurysms were most likely clipped using a fenestrated clip $(50.4 \%$ and $57.1 \%$ of the time, respectively). Placing the ipsilateral A2 in the opening of the clip is a safe and effective way to clip superiorly-pointing aneurysms. Similarly, placing the A1 branch in the fenestration is advantageous for some inferiorly-pointing aneurysms. ${ }^{28}$ In our series, however, only $16.5 \%$ of the inferiorly-pointing aneurysms were clip ligated using a fenestrated clip. When analyzing for outcomes based on clip usage, we found that fenestrated clips were not as advantageous as once thought; however, this could be limited by the fact that the use of a fenestrated clip might correlate with aneurysm complexity. It was clear that the need for more than one clip during surgery indicated an increase in complexity and worse outcomes for patients both at discharge and final follow-up.

\section{Ruptured ACoA Aneurysms: Glasgow Outcome Score Based on Presenting Hunt and Hess} Score

Our series showed worse GOS scores at discharge and at final follow-up among patients who had presented with poorer HH grades. This correlation is predictable and consistent with other studies in the literature. ${ }^{16,25}$

\section{Limitations}

This study is retrospective and therefore suffers from numerous limitations related to such form of reporting. In addition, this paper has not described the extensive decision making process that is required in managing these patients. The selection bias inherent in this report can limit its application to all patient groups. In addition, certain patients groups in 
our study included a very limited number of patients; this drawback can affect the overall validity of the statistical analysis.

\section{CONCLUSIONS}

The anatomic variability of the involved vasculature and the vital role of the surrounding neural structures necessitate careful scrutiny when deciding which aneurysms are best treated by surgical clipping or by endovascular treatment, and the specific characteristics that will ensure the success of each modality. An understanding of the unique anatomy of each aneurysm is critical for obtaining the best surgical results. 


\section{References}

1. Perlmutter D, Rhoton $\mathrm{AL}$, Jr. Microsurgical anatomy of the anterior cerebral-anterior communicating-recurrent artery complex. J Neurosurg. 1976;45(3):259-272.

2. Rhoton AL, Jr. Anatomy of saccular aneurysms. Surg Neurol. 1980;14(1):59-66.

3. Proust F, Debono B, Hannequin D, et al. Treatment of anterior communicating artery aneurysms: complementary aspects of microsurgical and endovascular procedures. $J$ Neurosurg. 2003;99(1):3-14.

4. Lawton MT. Surgical management of anterior communicating and anterior cerebral artery aneurysms. In: Quinones-Hinojosa A, ed. Schmidek and Sweet Operative Neurosurgical Techniques. Philadelphia: Elsevier Saunders; 2006.

5. Barker FG, 2nd, Amin-Hanjani S, Butler WE, et al. Age-dependent differences in shortterm outcome after surgical or endovascular treatment of unruptured intracranial aneurysms in the United States, 1996-2000. Neurosurgery. 2004;54(1):18-28; discussion 28-30.

6. Leipzig TJ, Morgan J, Horner TG, Payner T, Redelman K, Johnson CS. Analysis of intraoperative rupture in the surgical treatment of 1694 saccular aneurysms. Neurosurgery. 2005;56(3):455-468; discussion 455-468.

7. Kheireddin AS, Filatov Iu M, Belousova OB, et al. [Intraoperative rupture of cerebral aneurysm--incidence and risk factors]. Zh Vopr Neirokhir Im N N Burdenko. 2007(4):33-38; discussion 38.

8. Ohashi Y, Horikoshi T, Sugita M, Yagishita T, Nukui H. Size of cerebral aneurysms and related factors in patients with subarachnoid hemorrhage. Surg Neurol. 2004;61(3):239-245; discussion 245-237.

9. Hernesniemi J, Dashti R, Lehecka M, et al. Microneurosurgical management of anterior communicating artery aneurysms. Surg Neurol. 2008;70(1):8-28; discussion 29.

10. Lehecka M, Dashti R, Hernesniemi J, et al. Microneurosurgical management of aneurysms at the A2 segment of anterior cerebral artery (proximal pericallosal artery) and its frontobasal branches. Surg Neurol. 2008;70(3):232-246; discussion 246.

11. UCAS Japan Investigators, Morita A, Kirino $T$, et al. The natural course of unruptured cerebral aneurysms in a Japanese cohort. N Engl J Med. 2012;366(26):2474-2482.

12. Carter BS, Sheth S, Chang E, Sethl M, Ogilvy CS. Epidemiology of the size distribution of intracranial bifurcation aneurysms: smaller size of distal aneurysms and increasing size of unruptured aneurysms with age. Neurosurgery. 2006;58(2):217223; discussion 217-223.

13. Willinsky RA, Taylor SM, TerBrugge K, Farb RI, Tomlinson G, Montanera W. Neurologic complications of cerebral angiography: prospective analysis of 2,899 procedures and review of the literature. Radiology. 2003;227(2):522-528.

14. Campi A, Ramzi N, Molyneux AJ, et al. Retreatment of ruptured cerebral aneurysms in patients randomized by coiling or clipping in the International Subarachnoid Aneurysm Trial (ISAT). Stroke. 2007;38(5):1538-1544. 
15. Johnson AK, Munich SA, Heiferman DM, Lopes DK. Stent assisted embolization of 64 anterior communicating artery aneurysms. J Neurointerv Surg. 2013;5 Suppl 3:iii6265.

16. Hunt WE, Hess RM. Surgical risk as related to time of intervention in the repair of intracranial aneurysms. J Neurosurg. 1968;28(1):14-20.

17. Fisher CM, Roberson GH, Ojemann RG. Cerebral vasospasm with ruptured saccular aneurysm--the clinical manifestations. Neurosurgery. 1977;1(3):245-248.

18. Jennett $B$, Bond $M$. Assessment of outcome after severe brain damage. Lancet. 1975;1(7905):480-484.

19. Lai LT, Gragnaniello C, Morgan MK. Outcomes for a case series of unruptured anterior communicating artery aneurysm surgery. J Clin Neurosci. 2013;20(12):1688-1692.

20. Nanda A, Vannemreddy P. Surgical management of unruptured aneurysms: prognostic indicators. Surg Neurol. 2002;58(1):13-19; discussion 19-20.

21. Molyneux A, Kerr R, Stratton I, et al. International Subarachnoid Aneurysm Trial (ISAT) of neurosurgical clipping versus endovascular coiling in 2143 patients with ruptured intracranial aneurysms: a randomised trial. Lancet. 2002;360(9342):12671274.

22. Dashti R, Hernesniemi J, Lehto $H$, et al. Microneurosurgical management of proximal anterior cerebral artery aneurysms. Surg Neurol. 2007;68(4):366-377.

23. Abla AA, Wilson DA, Williamson RW, et al. The relationship between ruptured aneurysm location, subarachnoid hemorrhage clot thickness, and incidence of radiographic or symptomatic vasospasm in patients enrolled in a prospective randomized controlled trial. J Neurosurg. 2014;120(2):391-397.

24. Agrawal $A$, Kato $Y$, Chen $L$, et al. Anterior communicating artery aneurysms: an overview. Minim Invasive Neurosurg. 2008;51(3):131-135.

25. Debono B, Proust F, Langlois O, et al. [Ruptured anterior communicating artery aneurysm. Therapeutic options in 119 consecutive cases]. Neurochirurgie. 2004;50(1):21-32.

26. Hyun SJ, Hong SC, Kim JS. Side selection of the pterional approach for superiorly projecting anterior communicating artery aneurysms. J Clin Neurosci. 2010;17(5):592-596.

27. Suzuki M, Fujisawa H, Ishihara H, Yoneda H, Kato S, Ogawa A. Side selection of pterional approach for anterior communicating artery aneurysms--surgical anatomy and strategy. Acta Neurochir (Wien). 2008;150(1):31-39; discussion 39.

28. Zada G, Christian E, Liu CY, Giannotta SL. Fenestrated aneurysm clips in the surgical management of anterior communicating artery aneurysms: operative techniques and strategy. Clinical article. Neurosurg Focus. 2009;26(5):E7. 
Table 1: Characteristics of patients with ACoA aneurysms by artery of origin

\begin{tabular}{|c|c|c|c|c|c|c|c|}
\hline \multirow{4}{*}{$\mathrm{N}(\%)$} & \multicolumn{5}{|c|}{ ARTERY OF ORIGIN } & \multirow{4}{*}{ Statistic } & \multirow{4}{*}{$p$} \\
\hline & ACoA & A1 & A2 & $\mathrm{A} 1$ and $\mathrm{A2}$ & Total & & \\
\hline & 142 & 12 & 3 & 162 & 319 & & \\
\hline & (44.5) & (3.8) & $(0.9)$ & (50.8) & $(100.0)$ & & \\
\hline \multicolumn{8}{|l|}{ PATIENT CHARACTERISTICS } \\
\hline Average (SD) age in years & $\begin{array}{c}49.6 \\
(11.3)\end{array}$ & $\begin{array}{c}57.3 \\
(13.5)\end{array}$ & $58.0(5.2)$ & $\begin{array}{c}50.5 \\
(11.5)\end{array}$ & $\begin{array}{c}50.4 \\
(11.5)\end{array}$ & $F=2.16$ & 0.092 \\
\hline \% Caucasian & 85.2 & 91.7 & 66.7 & 90.1 & 87.8 & $*$ & $*$ \\
\hline$\%$ Female & 57.0 & 50.0 & 33.3 & 64.9 & 60.5 & $x^{2}=3.453$ & 0.327 \\
\hline$\%$ Family hx of aneurysm & 13.5 & 8.3 & 0.0 & 9.9 & 11.3 & $*$ & $*$ \\
\hline$\% \mathrm{Hx}$ of hypertension & 46.1 & 33.3 & 66.7 & 42.0 & 43.7 & $x^{2}=1.693$ & 0.638 \\
\hline$\% \mathrm{Hx}$ of hyperlipidemia & 9.2 & 8.3 & 0.0 & 9.9 & 9.4 & $*$ & $*$ \\
\hline$\% \mathrm{Hx}$ of diabetes & 6.4 & 8.3 & 0.0 & 2.5 & 4.4 & $*$ & $*$ \\
\hline$\% \mathrm{Hx}$ of smoking & 63.1 & 50.0 & 100.0 & 64.8 & 63.8 & $x^{2}=2.793$ & 0.425 \\
\hline \multicolumn{8}{|c|}{ PRESENTATION CHARACTERISTICS } \\
\hline$\%$ Ruptured & $\begin{array}{c}83.1 \\
(118 / 142)\end{array}$ & $\begin{array}{c}100.0 \\
(12 / 12)\end{array}$ & $66.7(2 / 3)$ & $\begin{array}{c}78.4 \\
(127 / 162)\end{array}$ & $\begin{array}{c}81.2 \\
(259 / 319)\end{array}$ & $*$ & $*$ \\
\hline $\begin{array}{l}\text { \% of Ruptured with frontal } \\
\text { lobe ICH }\end{array}$ & $\begin{array}{c}17.8 \\
(21 / 118)\end{array}$ & $8.3(1 / 12)$ & $\begin{array}{c}0.0 \\
(0 / 2)\end{array}$ & $\begin{array}{c}17.3 \\
(22 / 127)\end{array}$ & $\begin{array}{c}17.0 \\
(44 / 259)\end{array}$ & * & * \\
\hline$\%$ of ruptured with SAH & $\begin{array}{c}99.2 \\
(117 / 118)\end{array}$ & $\begin{array}{c}100.0 \\
(12 / 12)\end{array}$ & $\begin{array}{l}100.0 \\
(2 / 2)\end{array}$ & $\begin{array}{c}100.0 \\
(127 / 127)\end{array}$ & $\begin{array}{c}99.6 \\
(258 / 259)\end{array}$ & * & $*$ \\
\hline $\begin{array}{l}\text { Average (SD) Hunt Hess } \\
\text { upon admission (SAH cases } \\
\text { only) }\end{array}$ & $\begin{array}{c}2.0 \\
(1.2)\end{array}$ & $\begin{array}{c}2.6 \\
(1.4)\end{array}$ & $\begin{array}{c}2.5 \\
(2.1)\end{array}$ & $\begin{array}{c}2.1 \\
(1.3)\end{array}$ & $\begin{array}{c}2.1 \\
(1.3)\end{array}$ & $F=0.071$ & 0.547 \\
\hline $\begin{array}{l}\text { Average (SD) Fisher grade } \\
\text { (SAH cases only) }\end{array}$ & $\begin{array}{c}3.0 \\
(0.7)\end{array}$ & $\begin{array}{c}3.2 \\
(0.6)\end{array}$ & $\begin{array}{c}4.0 \\
(0.0)\end{array}$ & $\begin{array}{c}3.0 \\
(0.7)\end{array}$ & $\begin{array}{c}3.0 \\
(0.7)\end{array}$ & $F=1.63$ & 0.183 \\
\hline \multicolumn{8}{|l|}{ ANEURYSM CHARACTERISTICS } \\
\hline$\%$ Right side of origin & 41.1 & 50.0 & 33.3 & 49.0 & 45.4 & $x^{2}=2.007$ & 0.571 \\
\hline Average (SD) Size in $\mathrm{mm}$ & $\begin{array}{c}6.8 \\
(3.4)\end{array}$ & $\begin{array}{l}8.8 \\
(8.2)\end{array}$ & $10.0(0.0)$ & $\begin{array}{c}6.5 \\
(3.1)\end{array}$ & $\begin{array}{c}6.8 \\
(3.6)\end{array}$ & $F=2.21$ & 0.087 \\
\hline$\%$ Multi-lobed & 22.5 & 33.3 & 33.3 & 30.9 & 27.3 & * & $*$ \\
\hline$\%$ Calcified & 5.6 & 0.0 & 0.0 & 3.7 & 4.4 & * & $*$ \\
\hline$\%$ Previous coil & 1.4 & 0.0 & 0.0 & 0.6 & 1.0 & $*$ & $*$ \\
\hline $\begin{array}{l}\text { \% Remnant observed in } \\
\text { surgery }\end{array}$ & 7.1 & 8.3 & 33.3 & 8.9 & 8.3 & $*$ & $*$ \\
\hline \multicolumn{8}{|l|}{ OPERATIVE EVENTS } \\
\hline \% Ipsilateral approach ${ }^{\dagger}$ & 93.0 & 91.7 & 100.0 & 89.7 & 91.4 & $*$ & $*$ \\
\hline $\begin{array}{l}\text { \% Frontal lobe ICH } \\
\text { evacuated (ICH cases only) }\end{array}$ & $47.6(10 / 21)$ & $\begin{array}{c}0.0 \\
(0 / 1)\end{array}$ & na & $40.9(9 / 22)$ & $43.2(19 / 44)$ & $*$ & $*$ \\
\hline$\%$ Intraoperative rupture & 2.8 & 0.0 & 0.0 & 3.7 & 3.2 & $*$ & $*$ \\
\hline$\% 1$ straight clip & 17.1 & 8.3 & 0.0 & 23.9 & 20.0 & & \\
\hline$\% 1$ curved/angled clip & 25.0 & 50.0 & 0.0 & 22.6 & 24.5 & & \\
\hline$\% 1$ bayonette clip & 2.1 & 0.0 & 0.0 & 5.2 & 3.4 & $*$ & $*$ \\
\hline$\% 1$ fenestrated clip & 39.3 & 33.3 & 66.7 & 32.3 & 35.8 & & \\
\hline$\%$ More than 1 clip & 16.4 & 8.3 & 33.3 & 16.1 & 16.1 & & \\
\hline \% Temporary clip(s) used & 87.2 & 91.7 & 100.0 & 82.3 & 85.0 & $*$ & $*$ \\
\hline $\begin{array}{l}\text { Average (SD) number of } \\
\text { clips }\end{array}$ & $\begin{array}{c}1.2 \\
(0.4)\end{array}$ & $\begin{array}{c}1.1 \\
(0.3)\end{array}$ & $\begin{array}{c}1.3 \\
(0.6)\end{array}$ & $\begin{array}{c}1.2 \\
(0.4)\end{array}$ & $\begin{array}{c}1.2 \\
(0.4)\end{array}$ & $F=0.034$ & 0.794 \\
\hline$\%$ IOA only & 44.7 & 50.0 & 100.0 & 43.0 & 44.6 & $x^{2}=4.025$ & 0.259 \\
\hline \% ICG only & 2.1 & 0.0 & 0.0 & 7.0 & 4.5 & $*$ & $*$ \\
\hline \% Both IOA and ICG & 4.3 & 0.0 & 0.0 & 4.4 & 4.1 & $*$ & $*$ \\
\hline
\end{tabular}




\begin{tabular}{|c|c|c|c|c|c|c|c|}
\hline $\begin{array}{l}\% \text { Clip adjustment after } \\
\text { imaging }\end{array}$ & $27.8(20 / 72)$ & $16.7(1 / 6)$ & $\begin{array}{l}66.7 \\
(2 / 3)\end{array}$ & $\begin{array}{c}23.3 \\
(20 / 86)\end{array}$ & $\begin{array}{c}25.8 \\
(43 / 167)\end{array}$ & $*$ & $*$ \\
\hline \multicolumn{8}{|c|}{ POSTOPERATIVE COMPLICATIONS } \\
\hline$\%$ Hydrocephalus & 25.4 & 58.3 & 33.3 & 28.4 & 28.2 & $*$ & $*$ \\
\hline$\%$ Radiographic infarction & 22.9 & 8.3 & 33.3 & 18.6 & 20.3 & $*$ & $*$ \\
\hline$\%$ Postoperative deficits & 30.3 & 25.0 & 33.3 & 22.6 & 26.3 & $*$ & $*$ \\
\hline$\%$ Vasospasm & 15.5 & 41.7 & 0.0 & 19.8 & 18.5 & $*$ & $*$ \\
\hline \% Systemic complications & 11.3 & 25.0 & 33.3 & 11.1 & 11.9 & $*$ & $*$ \\
\hline $\begin{array}{l}\% \text { Remnant observed on } \\
\text { postoperative imaging }\end{array}$ & 5.2 & 8.3 & 33.3 & 7.1 & 6.6 & $*$ & $*$ \\
\hline \multicolumn{8}{|l|}{ CLINICAL OUTCOMES } \\
\hline $\begin{array}{l}\text { Average (SD) GOS at } \\
\text { Discharge }\end{array}$ & $\begin{array}{l}4.0^{\mathrm{A}} \\
(1.3)\end{array}$ & $\begin{array}{l}3.0^{A} \\
(1.2)\end{array}$ & $\begin{array}{l}3.3^{A, B} \\
(1.5)\end{array}$ & $\begin{array}{l}4.1^{B} \\
(1.2)\end{array}$ & $4.0(1.2)$ & 3.070 & 0.028 \\
\hline Average (SD) GOS at 6 & $4.7^{A}$ & $3.4^{\mathrm{A}}$ & $3.5^{\mathrm{A}, \mathrm{B}}$ & $4.5^{B}$ & $4.5(0.8)$ & $F=7310$ & 0.000 \\
\hline Months & (0.6) & $(1.1)$ & $(2.1)$ & $(0.8)$ & & & \\
\hline Average (SD) GOS at 1 Year & $\begin{array}{l}4.8^{A} \\
(0.5)\end{array}$ & $\begin{array}{l}3.0^{A} \\
(1.0)\end{array}$ & $\begin{array}{l}4.0^{\mathrm{A}, \mathrm{B}} \\
(1.4)\end{array}$ & $\begin{array}{l}4.7^{B} \\
(0.6)\end{array}$ & $4.6(0.7)$ & $F=9.190$ & 0.000 \\
\hline
\end{tabular}

ACoA, anterior communicating artery; F, F-statistic; GOS, Glasgow outcome score; hx, history; ICG, Indocyanine green fluorescent imaging; ICH, intracranial hemorrhage; IOA, intraoperative angiography; SAH, subarachnoid hemorrhage; SD, standard deviation; $\mathrm{X}^{2}$, Chi-square. Numbers in bold type are statistically significant.

*Chi-square invalid because expected frequencies were less than 1 or less than 5 in $20 \%$ of cells.

†13 ACOM and $16 \mathrm{~A} 1$ and A2 aneurysms are not represented because side of origin or surgical approach were not available.

¥Means that do not share a letter are significantly different (means with A are similar, and those with B are similar). 
Table 2: ACoA aneurysms by direction of projection

\begin{tabular}{|c|c|c|c|c|c|c|c|}
\hline \multirow{4}{*}{$\mathrm{N}(\%)$} & \multicolumn{5}{|c|}{ DIRECTION OF ANEURYSM PROJECTION } & \multirow{4}{*}{ Statistic } & \multirow{4}{*}{$p$} \\
\hline & Superior & Inferior & Anterior & Posterior & Total & & \\
\hline & 118 & 106 & 88 & 7 & 319 & & \\
\hline & $(37.0)$ & $(33.2)$ & $(27.6)$ & $(2.2)$ & $(100.0)$ & & \\
\hline \multicolumn{8}{|l|}{ PATIENT CHARACTERISTICS* } \\
\hline & $51.8^{\mathrm{A}}$ & $47.2^{\mathrm{B}}$ & $52.2^{\mathrm{A}}$ & $52.2^{A, B}$ & 50.4 & & 0006 \\
\hline Average (SD) age in years & $(12.0)$ & $(12.7)$ & (8.9) & $(6.0)$ & $(11.5)$ & $r=4.22$ & 0.006 \\
\hline$\%$ Caucasian & 88.1 & 88.7 & 85.2 & 100.0 & 87.7 & $\dagger$ & $\dagger$ \\
\hline$\%$ Female & 55.9 & 67.0 & 58.0 & 71.4 & 60.5 & $x^{2}=3.482$ & 0.323 \\
\hline$\%$ Family hx of aneurysm & 10.3 & 12.3 & 12.5 & 0.0 & 11.3 & + & $\dagger$ \\
\hline$\% \mathrm{Hx}$ of hypertension & 43.6 & 39.6 & 46.6 & 71.4 & 43.7 & $x^{2}=3.203$ & 0.361 \\
\hline$\% \mathrm{Hx}$ of hyperlipidemia & 11.1 & 10.4 & 5.7 & 14.3 & 9.4 & $\dagger$ & $\dagger$ \\
\hline$\% \mathrm{Hx}$ of diabetes & 2.6 & 5.7 & 5.7 & 0.0 & 4.4 & $\dagger$ & $\dagger$ \\
\hline$\% \mathrm{Hx}$ of smoking & 62.4 & 67.0 & 60.2 & 85.7 & 63.8 & $x^{2}=2.508$ & 0.474 \\
\hline \multicolumn{8}{|c|}{ PRESENTATION CHARACTERISTICS* } \\
\hline$\%$ Ruptured & $\begin{array}{c}81.4 \\
(96 / 118)\end{array}$ & $\begin{array}{c}85.9 \\
(91 / 106)\end{array}$ & $\begin{array}{c}78.4 \\
(69 / 88)\end{array}$ & $\begin{array}{l}42.9 \\
(3 / 7)\end{array}$ & $\begin{array}{c}81.2 \\
(259 / 319)\end{array}$ & $x^{2}=8.690$ & 0.034 \\
\hline $\begin{array}{l}\% \text { of ruptured with frontal } \\
\text { lobe } \mathrm{ICH}\end{array}$ & $12.5(12 / 96)$ & $\begin{array}{c}17.6 \\
(16 / 91)\end{array}$ & $\begin{array}{c}21.7 \\
(15 / 69)\end{array}$ & $\begin{array}{l}33.3 \\
(1 / 3)\end{array}$ & $\begin{array}{c}17.0 \\
(44 / 259)\end{array}$ & $\dagger$ & $\dagger$ \\
\hline $\begin{array}{l}\text { Average (SD) Hunt Hess } \\
\text { upon admission (SAH cases } \\
\text { only) }\end{array}$ & $\begin{array}{c}2.3 \\
(1.3)\end{array}$ & $\begin{array}{c}2.0 \\
(1.3)\end{array}$ & $\begin{array}{c}1.9 \\
(1.2)\end{array}$ & $\begin{array}{l}2.0 \\
(1.0)\end{array}$ & $\begin{array}{c}2.1 \\
(1.3)\end{array}$ & $F=1.68$ & 0.172 \\
\hline $\begin{array}{l}\text { Average (SD) Fisher grade } \\
\text { (SAH cases only) }\end{array}$ & $\begin{array}{l}3.0^{B} \\
(0.6)\end{array}$ & $\begin{array}{l}2.9^{B} \\
(0.8)\end{array}$ & $\begin{array}{l}3.2^{\mathrm{A}} \\
(0.7)\end{array}$ & $\begin{array}{l}2.5^{\mathrm{A}, \mathrm{B}} \\
(0.7)\end{array}$ & $\begin{array}{c}3.0 \\
(0.7)\end{array}$ & $F=2.66$ & 0.049 \\
\hline \multicolumn{8}{|l|}{ ANEURYSM CHARACTERISTICS* } \\
\hline$\%$ Right side of origin & 41.3 & 51.0 & 44.0 & 42.9 & 45.4 & $X^{2}=2.088$ & 0.554 \\
\hline Average (SD) size in $\mathrm{mm}$ & $\begin{array}{l}6.9^{B, C} \\
(3.5)\end{array}$ & $\begin{array}{l}5.9^{C} \\
(2.5)\end{array}$ & $\begin{array}{l}7.2^{\mathrm{B}} \\
(3.7)\end{array}$ & $\begin{array}{l}11.8^{\mathrm{A}} \\
(10.8)\end{array}$ & $\begin{array}{c}6.8 \\
(3.6)\end{array}$ & $F=6.08$ & 0.000 \\
\hline$\%$ Multi-lobed & 28.0 & 30.2 & 22.7 & 28.6 & 27.3 & $x^{2}=1.406$ & 0.704 \\
\hline$\%$ Calcified & 3.4 & 1.9 & 9.1 & 0.0 & 4.4 & + & + \\
\hline$\%$ Previous coil & 0.0 & 1.9 & 1.2 & 0.0 & 1.0 & + & + \\
\hline $\begin{array}{l}\text { \% Remnant observed in } \\
\text { surgery }\end{array}$ & 6.0 & 6.7 & 11.6 & 28.6 & 8.3 & $\dagger$ & $\dagger$ \\
\hline \multicolumn{8}{|l|}{ OPERATIVE EVENTS } \\
\hline \% Ipsilateral approach $\ddagger$ & 90.8 & 91.9 & 92.0 & 85.7 & 91.4 & $\dagger$ & $\dagger$ \\
\hline$\%$ Frontal lobe ICH & 33.3 & 56.3 & 40.0 & 0.0 & 43.2 & + & + \\
\hline evacuated (ICH cases only) & $(4 / 12)$ & $(9 / 16)$ & $(6 / 15)$ & $(0 / 1)$ & $(19 / 44)$ & & \\
\hline$\%$ Intraoperative rupture & 5.9 & 2.8 & 0.0 & 0.0 & 3.1 & $\dagger$ & $\dagger$ \\
\hline$\%$ One straight clip & 14.5 & 32.0 & 13.3 & 14.3 & 20.0 & + & + \\
\hline$\%$ One curved/angled clip & 18.8 & 32.0 & 25.3 & 0.0 & 24.5 & & \\
\hline$\%$ One bayonette clip & 1.7 & 5.8 & 3.6 & 0.0 & 3.6 & & \\
\hline$\%$ One fenestrated clip & 50.4 & 16.5 & 37.4 & 57.1 & 35.8 & & \\
\hline$\%$ More than 1 clip & 14.5 & 13.6 & 20.5 & 28.6 & 16.1 & & \\
\hline \% Temporary clip(s) used & 88.9 & 80.8 & 84.9 & 85.7 & 85.0 & & \\
\hline $\begin{array}{l}\text { Average (SD) number of } \\
\text { clips }\end{array}$ & $\begin{array}{c}1.2 \\
(0.4)\end{array}$ & $\begin{array}{c}1.2 \\
(0.4)\end{array}$ & $\begin{array}{c}1.2 \\
(0.4)\end{array}$ & $\begin{array}{l}1.3 \\
(0.5)\end{array}$ & $\begin{array}{c}1.2 \\
(0.4)\end{array}$ & $F=0.67$ & 0.569 \\
\hline$\%$ Intraoperative rupture & 5.9 & 2.8 & 0.0 & 0.0 & 3.1 & + & + \\
\hline$\%$ IOA only & 57.3 & 26.9 & 46.5 & 71.4 & 44.6 & $x^{2}=22.915$ & 0.000 \\
\hline$\%$ ICG only & 2.6 & 3.9 & 8.1 & 0.0 & 4.5 & + & + \\
\hline$\%$ Both IOA \& ICG & 1.7 & 4.8 & 7.0 & 0.0 & 4.1 & $\dagger$ & + \\
\hline
\end{tabular}




\begin{tabular}{|c|c|c|c|c|c|c|c|}
\hline $\begin{array}{l}\% \text { Clip adjustment after } \\
\text { imaging }\end{array}$ & $\begin{array}{c}25.0 \\
(18 / 72)\end{array}$ & $\begin{array}{c}16.2 \\
(6 / 37)\end{array}$ & $\begin{array}{c}32.1 \\
(17 / 53)\end{array}$ & $\begin{array}{l}40.0 \\
(2 / 5)\end{array}$ & $\begin{array}{c}25.8 \\
(43 / 167)\end{array}$ & $x^{2}=3.420$ & 0.331 \\
\hline \multicolumn{8}{|c|}{ POSTOPERATIVE COMPLICATIONS } \\
\hline \% Hydrocephalus & 28.8 & 20.8 & 36.4 & 28.6 & 28.2 & $x^{2}=5.819$ & 0.121 \\
\hline$\%$ Radiographic infarction & 19.7 & 16.2 & 26.1 & 16.7 & 20.3 & $x^{2}=3.032$ & 0.387 \\
\hline \% Clinical stroke & 9.3 & 5.8 & 13.8 & 0.0 & 9.2 & $\dagger$ & $\dagger$ \\
\hline \% Postoperative deficits & 29.9 & 20.0 & 27.6 & 42.9 & 26.3 & $x^{2}=4.006$ & 0.261 \\
\hline$\%$ Vasospasm & 17.8 & 17.0 & 19.3 & 42.9 & 18.5 & $x^{2}=2.995$ & 0.392 \\
\hline \% Systemic complications & 12.7 & 8.5 & 15.9 & 0.0 & 11.9 & $\dagger$ & $\dagger$ \\
\hline $\begin{array}{l}\% \text { Remnant observed on } \\
\text { postoperative imaging }\end{array}$ & 4.4 & 5.1 & 10.5 & 16.7 & 6.7 & $\dagger$ & $\dagger$ \\
\hline \multicolumn{8}{|l|}{ CLINICAL OUTCOMES } \\
\hline $\begin{array}{l}\text { Average (SD) GOS at } \\
\text { discharge }\end{array}$ & $\begin{array}{c}3.9 \\
(1.3)\end{array}$ & $\begin{array}{c}4.2 \\
(1.2)\end{array}$ & $\begin{array}{c}3.9 \\
(1.3)\end{array}$ & $\begin{array}{c}4.4 \\
(0.5)\end{array}$ & $\begin{array}{c}4.0 \\
(1.2)\end{array}$ & $F=2.00$ & 0.114 \\
\hline $\begin{array}{l}\text { Average (SD) GOS at } 6 \\
\text { months }\end{array}$ & $\begin{array}{c}4.4 \\
(0.9)\end{array}$ & $\begin{array}{l}4.7 \\
(0.7)\end{array}$ & $\begin{array}{c}4.5 \\
(0.7)\end{array}$ & $\begin{array}{c}4.8 \\
(0.4)\end{array}$ & $\begin{array}{l}4.5 \\
(0.8)\end{array}$ & $F=1.22$ & 0.304 \\
\hline Average (SD) GOS at 1 year & $\begin{array}{c}4.5 \\
(0.6)\end{array}$ & $\begin{array}{c}4.8 \\
(0.6)\end{array}$ & $\begin{array}{c}4.5 \\
(0.8)\end{array}$ & $\begin{array}{c}5.0 \\
(0.0)\end{array}$ & $\begin{array}{c}4.6 \\
(0.7)\end{array}$ & $F=1.70$ & 0.172 \\
\hline
\end{tabular}

Abbreviations: ACoA, anterior communicating artery; F, F-Statistic; GOS, Glasgow outcome score; hx, history; ICG, Indocyanine green fluorescent imaging; ICH, intracranial hemorrhage; IOA, intraoperative angiography; $\mathrm{SAH}$, subarachnoid hemorrhage; SD, standard deviation; $X^{2}$, Chi-square. Numbers in bold type are statistically significant.

*Means that do not share a letter are significantly different (means with A are similar, and those with B are similar). +Chi-Square invalid because expected frequencies were less than 1 or less than 5 in $20 \%$ of cells.

$\ddagger$ Nine superior, 7 inferior, and 13 anterior aneurysms are not represented because side of origin or surgical approach were not available. 
Table 3: GOS Discharge outcomes by ACoA aneurysm projection and surgical approach

\begin{tabular}{|c|c|c|c|c|c|}
\hline ACoA Projection & Surgical Approach & $\mathbf{N}$ & $\%$ with Acceptable Outcome & Statistic & $p$ \\
\hline Posterior & Ipsilateral & 6 & 100.0 & & \\
\hline Superior & Contralateral & 10 & 100.0 & & \\
\hline Inferior & Ipsilateral & 91 & 75.8 & & \\
\hline Anterior & Contralateral & 6 & 66.7 & & 0.015 \\
\hline Anterior & Ipsilateral & 68 & 63.2 & & \\
\hline Superior & Ipsilateral & 99 & 58.6 & & \\
\hline Inferior & Contralateral & 8 & 50.0 & & \\
\hline All & All & 289 & 67.5 & & \\
\hline
\end{tabular}

Abbreviations: ACOA, anterior communicating artery; F, F-Statistic; GOS, Glasgow outcome score; $\mathrm{X}^{2}$, Chi-square. The proportion of acceptable GOS outcomes of 4 or 5 is compared for each combination of ACoA aneurysm projection and surgical approach. Note: One posterior contralateral case (with and acceptable GOS outcome) was removed from the analysis due to insufficient $\mathrm{N}$ for this category. 13 anterior, 6 inferior, and 9 superior projecting aneurysms are not represented because side of origin or surgical approach were not available. Numbers in bold type are statistically significant. 
Table 4: Patients with ruptured ACoA complex aneurysms: clinical outcomes by indicators of aneurysm complexity

\begin{tabular}{|c|c|c|c|c|}
\hline & $\mathrm{n}$ & $\begin{array}{c}\text { GOS } \\
\text { at Discharge* }\end{array}$ & $\mathbf{n}$ & Final GOS* \\
\hline Artery of Origin & & $F=1.82, p=0.144$ & & $F=2.17, p=0.092$ \\
\hline ACOM & 118 & $3.8(1.3)$ & 118 & $4.1(1.3)^{\mathrm{A}}$ \\
\hline A1 & 12 & $3.0(1.2)$ & 12 & $3.2(1.3)^{\mathrm{B}}$ \\
\hline A2 & 2 & $3.5(2.1)$ & 2 & $4.0(1.4)^{\mathrm{A}, \mathrm{B}}$ \\
\hline$A 1$ and $A 2$ & 126 & $3.9(1.2)$ & 126 & $4.1(1.2)^{A}$ \\
\hline Direction of Projection & & $F=1.83, p=0.142$ & & $F=1.77, p=0.153$ \\
\hline Superior & 95 & $3.7(1.3)$ & 95 & $4.0(1.3)$ \\
\hline Inferior & 91 & $4.1(1.2)$ & 91 & $4.3(1.2)$ \\
\hline Anterior & 69 & $3.7(1.3)$ & 69 & $3.9(1.3)$ \\
\hline Posterior & 3 & $4.3(0.6)$ & 3 & $4.7(0.6)$ \\
\hline Frontal lobe ICH & & $t=2.75, p=0.008$ & & $t=1.75, p=0.085$ \\
\hline Yes & 44 & $3.3(1.4)$ & 44 & $3.7(1.6)$ \\
\hline No & 214 & $3.9(1.2)$ & 214 & $4.2(1.2)$ \\
\hline Evacuation of ICH (ICH cases only) & & $0.34, p=0.736$ & & $t=0.26, p=0.798$ \\
\hline Yes & 19 & $3.2(1.5)$ & 19 & $3.6(1.7)$ \\
\hline No & 2 & $3.4(1.4)$ & 25 & $3.8(1.5)$ \\
\hline Calcification & & $t=0.92, p=0.377$ & & $t=0.64, p=0.535$ \\
\hline Yes & 12 & $3.5(1.2)$ & 12 & $3.8(1.3)$ \\
\hline No & 246 & $3.8(1.3)$ & 246 & $4.1(1.3)$ \\
\hline Clip Type & & $F=3.49, p=0.009$ & & $F=2.20, p=0.069$ \\
\hline 1 straight clip & 54 & $4.1(1.3)^{\mathrm{A}}$ & 54 & $4.2(1.3)^{A, B}$ \\
\hline 1 curved/angled clip & 71 & $4.1(1.1)^{\mathrm{A}}$ & 71 & $4.3(1.1)^{\mathrm{A}}$ \\
\hline 1 bayonette clip & 9 & $3.7(1.1)^{A, B}$ & 9 & $3.9(1.1)^{\mathrm{A}, \mathrm{B}}$ \\
\hline 1 fenestrated clip & 102 & $3.6(1.3)^{\mathrm{B}}$ & 102 & $3.9(1.3)^{A, B}$ \\
\hline More than 1 clip & 18 & $3.3(1.5)^{\mathrm{B}}$ & 18 & $3.6(1.7)^{A, B}$ \\
\hline Temporary Clip & & $t=0.23, p=0.819$ & & $t=0.28, p=0.778$ \\
\hline
\end{tabular}


Yes

No

Clip adjustment after imaging

Yes

No

$$
225
$$

30

$$
3.8(1.3)
$$$$
3.9(1.4)
$$$$
t=1.04, p=0.305
$$

32

104
$3.4(1.5)$

$3.7(1.3)$
225

30

$4.1(1.4)$

$t=0.87, p=0.388$

32

104
3.7 (1.5)

$3.9(1.3)$

Abbreviations: F, F-statistic ; GOS, Glasgow outcome score; ICH, intracranial hemorrhage; t, Student's t-test statistic. Numbers in bold type are statistically significant.

* Means that do not share a letter are significantly different (means with A are similar, and those with B are similar). 
Table 5: Patients with ruptured ACoA aneurysms: Glasgow outcome score based on presenting Hunt and Hess score

\begin{tabular}{lllll}
\hline $\begin{array}{l}\text { Hunt and Hess } \\
\text { Score }\end{array}$ & \multicolumn{2}{l}{ Discharge GOS } & \multicolumn{2}{l}{ GOS at latest follow-up } \\
\cline { 2 - 5 } & \% Acceptable & Average & \% Acceptable & Average \\
\hline 1 & $81(108 / 133)$ & 4.28 & $89(118 / 133)$ & 4.89 \\
2 & $59(13 / 22)$ & 3.59 & $68(15 / 22)$ & 3.72 \\
3 & $55(29 / 53)$ & 3.64 & $64(34 / 53)$ & 3.89 \\
4 & $30(12 / 40)$ & 3.03 & $50(20 / 40)$ & 3.43 \\
5 & $11(1 / 9)$ & 2.22 & $33(3 / 9)$ & 2.67
\end{tabular}

Abbreviation: GOS, Glasgow outcome score. 


\section{Abbreviations}

$\mathrm{ACoA}$, anterior communicating artery

ANOVA, analysis of variance

CTA, computed tomography angiography

DSA, digital subtraction angiography

GOS, Glasgow outcome score

$\mathrm{HH}$, Hunt and Hess

hx, history

ICG, Indocyanine green fluorescent imaging

$\mathrm{ICH}$, intracranial hemorrhage

IOA, intraoperative angiography

MRA, magnetic resonance angiography

$\mathrm{SAH}$, subarachnoid hemorrhage

SD, standard deviation 